\title{
Construct validity of Comprehensive High-Level Activity Mobility Predictor (CHAMP) for male servicemembers with traumatic lower- limb loss
}

\author{
Robert S. Gailey, PhD, PT; ${ }^{1-2^{*}}$ COL (Ret) Charles Scoville, PT, DPT; ${ }^{3}$ Ignacio A. Gaunaurd, PhD, MSPT; ${ }^{1-2}$ \\ Michele A. Raya, PhD, PT, SCS, ATC; ${ }^{2}$ Alison A. Linberg, DPT, ATC; ${ }^{3}$ COL (Ret) Paul D. Stoneman, PhD, PT, \\ MPT, DPT, OCS, SCS; ${ }^{3}$ MAJ (Ret) Stuart M. Campbell, MPT; ${ }^{4}$ Kathryn E. Roach, PhD, PT $^{2}$ \\ ${ }^{1}$ Functional Outcomes Research and Evaluation Center, Miami Department of Veterans Affairs Healthcare System, \\ Miami, FL; ${ }^{2}$ Department of Physical Therapy, Miller School of Medicine, University of Miami, Coral Gables, FL; \\ ${ }^{3}$ Military Advanced Training Center, Walter Reed Army Medical Center, Washington, DC; ${ }^{4}$ Center for the Intrepid, \\ Brooke Army Medical Center, San Antonio, TX
}

\begin{abstract}
This study examined the convergent construct validity of a new performance-based assessment instrument called the Comprehensive High-Level Activity Mobility Predictor (CHAMP) as a measure of high-level mobility in servicemembers (SMs) with traumatic lower-limb loss (LLL). The study was completed by 118 SMs. Convergent construct validity of the CHAMP was established using the 6-minute walk test (6MWT) as a measure of overall mobility and physical function and the Amputee Mobility Predictor (AMP) as a measure of basic prosthetic mobility. The known group methods construct validity examined disparities in high-level mobility capability among SMs with different levels of LLL. The CHAMP score demonstrated a strong positive relationship between 6MWT distance $(r=0.80, p<0.001)$ and AMP score ( $r=0.87, p<0.001$ ), respectively. In addition, the CHAMP can discriminate between different levels of LLL. Study findings support the CHAMP as a valid performance-based assessment instrument of high-level mobility for SMs with traumatic LLL.
\end{abstract}

Key words: 6-minute walk test, agility, Amputee Mobility Predictor, CHAMP, construct validity, high-level mobility, lowerlimb loss, military personnel, OIF/OEF, traumatic amputation.

\section{INTRODUCTION}

Mobility is defined by the International Classification of Functioning, Disability, and Health (ICF) as moving

\footnotetext{
Abbreviations: 6MWT = 6-minute walk test; AMP = Amputee Mobility Predictor; ANOVA = analysis of variance; ATS = American Thoracic Society; BAMC = Brooke Army Medical Center; BLLA = bilateral lower-limb amputation; BTFA = bilateral transfemoral amputation; BTTA = bilateral transtibial amputation; CHAMP = Comprehensive High-Level Activity Mobility Predictor; ESST = Edgren Side Step Test; IAT = Illinois Agility Test; ICF = International Classification of Functioning, Disability, and Health; LLL = lower-limb loss; MFCL = Medicare Functional Classification Level; SD = standard deviation; SLS = Single Limb Stance; SM = servicemember; $\mathrm{TBI}=$ traumatic brain injury; TFA = unilateral transfemoral amputation; TTA = unilateral transtibial amputation; VA = Department of Veterans Affairs; WRAMC = Walter Reed Army Medical Center.

*Address all correspondence to Robert S. Gailey, PhD, PT; Department of Physical Therapy, Miller School of Medicine, University of Miami, 5915 Ponce de Leon Blvd, Plummer Building, 5th floor, Coral Gables, FL 33146; 305-2844535; fax: 305-378-4107. Email: rgailey@miami.edu http://dx.doi.org/10.1682/JRRD.2012.05.0100
} 
by changing body position or location or by transferring from one place to another by carrying, moving, or manipulating objects by walking, running, or climbing, and by using various forms of transportation [1]. Using the ICF mobility definition as a foundation and considering the study population being examined, which is servicemembers (SMs) with traumatic lower-limb loss (LLL), we defined "high-level mobility" as advanced-rank function involving change in body position or location by transferring from one place to another by rapidly walking or running. The U.S. Army defines several physical performance factors required for mobility, such as balance, postural stability, coordination, power, speed, and agility [2]. The most appropriate units of measure to quantify the combination of physical performance factors identified for mobility are time and distance, where a decrease in time to cover a specific distance is an indicator of increased mobility and is often associated with improved function [3]. Consequently, multidirectional agility tasks that require greater power and speed of movement similar to the demands on the musculoskeletal system associated with athletic or military maneuvers would be considered high-level mobility.

Existing literature lacks research utilizing performance-based outcome measures to examine high-level mobility differences between varying levels of LLL that include people with unilateral and bilateral amputation [4]. Self-report-based outcome measures, such as questionnaires, found the majority of people with amputation, regardless of level of amputation or number of limbs lost, had little to no difficulty walking on a level-surface, but differences emerged with difficult tasks such as fast walking, inclined ambulation, and stairs [4-6]. Whereas self-report outcome measures are ideal for determining an individual's perception of his or her function when direct observation is not possible [7-10], the qualification or self-appraisal of higher-level mobility can be vague and vary greatly, and therefore we determined to employ only performance-based measures to adequately quantify the person with amputation's physical capabilities with a prosthesis.

The current issue with clinically appropriate performance-based outcome measures for the amputee population is that the vast majority of outcome measures are designed for lower levels of mobility, frequently targeting patients during early rehabilitation or the geriatric population [11-15]. The few tests that assess high-level mobility target athletes during the sport reentry phase of rehabilitation, which requires sprinting skills, hopping, and other maneuvers that would not be appropriate for healing tissues [16-19]. Moreover, specific higher-level tests are not comprehensive in nature and test only one plane of motion or skill. Many people who experience limb loss as a result of trauma are employed in high-risk professions such as the military, firefighting, and law enforcement. Some would like to return to their chosen professions but must demonstrate to themselves and others that they can do so without putting themselves and others at risk.

The Comprehensive High-Level Activity Mobility Predictor (CHAMP) was created to measure high-level mobility in SMs with traumatic LLL. To be useful as an outcome measure for this unique population, the CHAMP had to quantify and measure change in function throughout the rehabilitation process and provide information relevant in determining readiness to return to high-level activity. In a previously reported study, the CHAMP demonstrated excellent test-retest and interrater reliability in a population of SMs with traumatic LLL [20]. Having established the CHAMP's reliability, it was necessary to validate the CHAMP to establish the degree of confidence that can be placed on inferences made about SMs with amputation's high-level mobility performance [21].

It was impossible to examine the criterion validity of the CHAMP because no "gold-standard" measure of high-level mobility had been identified. However, it was possible to explore convergent construct validity by examining the relationship between CHAMP scores and established measures of mobility in the amputee population, such as the 6-minute walk test (6MWT) and Amputee Mobility Predictor (AMP). We assumed that as mobility and overall function improves throughout the healing and rehabilitation process, CHAMP scores would increase along with greater distance ambulated in $6 \mathrm{~min}$ and higher AMP scores. Therefore, if the CHAMP is a valid measure of high-level mobility, it should be strongly correlated with the 6MWT and AMP.

The 6MWT is considered a measure of overall mobility, endurance, and physical functioning in the adult and geriatric population and has been described as a physical performance measure of functional ambulation in people with LLL [22-23]. The AMP has been shown to be a measure of basic mobility in people with LLL [20]. Both the 6MWT and the AMP have excellent reliability 
for people with LLL and can differentiate between Medicare Functional Classification Levels (MFCLs) [20].

The MFCL is an index designed for the association between the mobility of a person with limb loss and the prosthetic foot and/or knee component prescription that theoretically would best match functional ability. When the AMP scoring system was developed, no reason existed to exceed the five categories of the MFCL. However, as rehabilitation strategies and prosthetic components improved over time, so did the expectations of physical performance for people with limb loss. At Walter Reed Army Medical Center (WRAMC), the majority of SMs with limb loss were achieving high scores on the AMP early in the rehabilitation process after receiving a prosthesis, and a ceiling was observed [24]. The physical capabilities of SMs has improved to the level that approximately 17 percent of those with limb loss either qualified for Continuation on Active Duty or Continuation on Active Reserve, or were determined to be Fit for Duty [25-26]. There was a clear need for a measure of performance beyond the AMP. The 6MWT does not have a maximum distance but is limited to walking in a single direction and does not permit running. We determined that a need existed for a clinically friendly performancebased test that could quantify the ability to move in all three planes of motion, may be implemented during early rehabilitation, could be performed by walking or sprinting, did not require any hopping, and would include the skills necessary for military or similar physically demanding professions or sports regardless of age.

The CHAMP, as a performance-based outcome measure, should objectively determine whether differences in high-level mobility capabilities exist between SMs with different level of amputation. The ability to determine differences in mobility between the level(s) and number of limbs amputated would help determine realistic goals for the clinician and SM. For example, clinicians could outline rehabilitation programs that focused on improving multidirection mobility, with practical expectations for the lower and upper limits of mobility, in SMs with either unilateral or bilateral amputation and for specific levels of amputation. Objectives for all concerned could be obtained with less frustration, based on unobtainable goals not being met or the SM not completing rehabilitation with a sense of failure, because they have a measure of high-level mobility with which they could gauge their individual capabilities.
The purpose of this study was to examine the convergent construct validity of the CHAMP as a measure of high-level mobility based on the performance of SMs with traumatic LLL. We hypothesized that if the CHAMP was a valid measure of high-level mobility in SM with limb loss, CHAMP scores would correlate with the $6 \mathrm{MWT}$ distance and AMP scores and differ among the levels of amputation.

\section{METHODS}

\section{Study Design}

This cross-sectional, multisite study was conducted at WRAMC in Washington, DC; Center for the Intrepid at Brooke Army Medical Center (BAMC), San Antonio, Texas; and Womack Army Medical Center, Fort Bragg, North Carolina. We studied a sample of 118 SMs with LLL. Participants were either Active Duty or retired male SMs between the ages of 18 and $40 \mathrm{yr}$ with traumatic LLL characterized by level as unilateral transtibial amputation (TTA), unilateral transfemoral amputation (TFA), bilateral transtibial amputation (BTTA), bilateral transfemoral amputation (BTFA), or a combination of transtibial and transfemoral amputation (TTA/TFA). Participants were medically stable with a properly fitting prosthesis and demonstrated a minimal level of function defined as an AMP score of at least 37 points and/or 6MWT of at least $250 \mathrm{~m}$. Five participants (four with BTFA and one with TTA/TFA) scored less than 37 on the AMP (either a 32 or 35). Because these SMs all ambulated greater than $250 \mathrm{~m}$ in $6 \mathrm{~min}$, they were included in the study sample. Participants were excluded if they had spinal cord injury; upper-limb loss; peripheral nerve injury limiting function; orthopedic, cardiopulmonary, or contralateral limb injuries limiting mobility or exercise tolerance; or inability to follow commands or physical limitations because of traumatic brain injury (TBI). All participants had been evaluated at the medical treatment facilities with the most current evaluation procedure for TBI available at the time of their rehabilitation, and a military physical therapist completed their medical history interview prior to testing to ensure that TBI or other medical conditions were not an issue. Although TBI had been evaluated postinjury and throughout the rehabilitation process by military medical personnel, the effects of TBI were not further quantified or screened for beyond the subjective interview at the time of testing. All participants 
could follow commands and did not present with observable upper motor neuron complications that would impede physical performance.

\section{Study Procedures}

Prior to signing Institutional Review Board-approved informed consent and protected health information forms, a research investigator reviewed and explained to each participant eligibility criteria, methodology, confidentiality, and potential risks involved.

The participants were tested on one occasion and were required to wear their daily-use prosthesis and standard physical training gear (T-shirt, shorts, socks, and sneakers). Two physical therapists who were currently working or had previously worked in the Armed Forces Amputee Patient Care Program Rehabilitation Centers at WRAMC and BAMC interviewed the participants. Information such as demographic characteristics, current medical conditions, symptoms, and pain and anthropometric measurements such as height, body mass, and waist circumference were collected for all participants.

\section{Outcome Measures}

\section{Comprehensive High-Level Activity Mobility Predictor}

The four tests that make up the CHAMP are the Single Limb Stance (SLS), Edgren Side Step Test (ESST), TTest, and Illinois Agility Test (IAT) [27-34]. Testing was administered either outdoors on a smooth surface under a covered patio or indoors within a gymnasium on a hardwood floor. Teams of two raters observed the participants from separate unobstructed vantage points. Each participant performed the CHAMP independently to avoid competition. A seated rest period of up to 2 min between each CHAMP item was required. Participants were asked to perform each test twice, with the best score of the two trials selected for data analysis. In the event a participant was unable to successfully complete a test in two trials because of a disqualification or a fall, a third trial was permitted. To maintain consistency, we determined prior to testing to utilize the data from one rater for analysis of CHAMP performance. The best times/points reported by the selected rater for each individual CHAMP item (SLS, ESST, T-Test, and IAT) were converted to a 0-10 scoring system, with higher scores indicating better performance. The scores for each individual test were added together to produce a composite CHAMP score with a 0-40 scoring range. Higher scores indicated better performance on the CHAMP [27].

\section{6-Minute Walk Test}

The 6MWT is a measure of overall functional mobility and cardiopulmonary and musculoskeletal endurance. Two different research staff members administered it at each testing site after each participant completed the CHAMP test. A rest period of 10 min was given to each participant prior to beginning the 6MWT. The 6MWT was performed indoors on a smooth, flat surface. Administration of the 6MWT was largely consistent with recommendations by the American Thoracic Society (ATS). The participants were reminded that the 6MWT was "not a cool down" and were given standardized instructions consistent with ATS guidelines that encouraged the participant "to cover as much distance as possible," which included a demonstration of the task. The track distance (200 ft/61 m to $212 \mathrm{ft} / 65 \mathrm{~m}$ ) and rectangular shape eliminated the need to perform a pivot turn and allowed participants to circle the course without interruption of cadence [35]. The course configuration was consistent and was not considered a source of variability in performance [36]. At the completion of the 6MWT, the distance walked was measured and recorded in meters.

\section{Amputee Mobility Predictor}

The AMP was administered by the same research investigator and licensed physical therapist at all three data collection sites. It was performed indoors on a flat surface and administered as previously described [6]. The AMP contains 20 items progressing in level of difficulty: items 1 and 2 test the participant's ability to maintain sitting balance unsupported and reaching; items 3 through 7 examine the participant's ability to maintain balance while performing chair-to-chair transfers, sit-to-stand activities, and maintenance of quiet standing; items 8 through 13 are more challenging activities related to standing balance that include single-limb stance, modified reach test, nudge test, picking an object up from the floor, and standing with eyes closed; and items 14 through 20 evaluate various components of gait such as gait initiation, step length, step continuity, ability to vary cadence, transverse over an obstacle, turns, and ascending and descending stairs. All item scores were added together to produce an AMP score for each individual. 


\section{Statistical Analysis}

Statistical analyses were performed using SAS version 9.1 (SAS Institute Inc; Cary, North Carolina). Descriptive statistics were used to characterize the study sample. The convergent construct validity of the CHAMP was examined by calculating a Pearson product-moment correlation coefficient to determine the strength and direction of the relationship between the CHAMP score and 6MWT distance. The relationship between the CHAMP and AMP was also determined with the intention of ascertaining whether a continuum of mobility could be established with a basic mobility and high-level mobility measure.

Frequency distribution data were analyzed to determine the number of SMs with LLL who performed in the range of SMs without LLL for the CHAMP items and CHAMP score. CHAMP performance data for SMs without LLL, which were previously collected when establishing the reliability of the CHAMP, were used for this analysis [27].

The construct validity of the CHAMP was established using the known group methods. Analysis of variance (ANOVA), followed by post hoc Tukey honestly significant differences, was calculated to compare CHAMP item scores and total CHAMP score among those with TTA, TFA, and bilateral lower-limb amputation (BLLA).

\section{RESULTS}

The baseline characteristics of the 118 participants are described in Table 1, which includes mean age, height, body mass, time since injury, and military status at time of testing. Of note, 60 participants had TTA, 32 had TFA, 26 had BLLA (12 had BTTA, 7 had BTFA, and 7 had TTA/TFA). Of the participants, 42 (36\%) had completed skilled rehabilitation, 32 had returned to Active Duty (27\%), and 44 (37\%) had retired from the Armed Forces.

Common medical comorbidities reported by the SMs with LLL are listed in Table 2. On the day of testing, prior to performing the CHAMP, all participants completed a visual analog scale $(10 \mathrm{~mm}$ scale with $0=$ no pain to $10=$ worst pain imaginable), to assess pain in the upper and lower limb, neck, back, and residual limb. All participants responded with "0" or no pain.

The mean \pm standard deviation (SD) for the 6MWT distance for all participants was $598.1 \pm 108.5 \mathrm{~m}$ with a minimum and maximum ambulation distance of $264.1 \mathrm{~m}$ and $857.9 \mathrm{~m}$, respectively. The average 6MWT distance

Table 1.

Characteristics of servicemembers with traumatic lower-limb loss.

\begin{tabular}{lcr}
\hline \multicolumn{1}{c}{ Characteristic } & $\boldsymbol{n} \mathbf{( \% )}$ & Mean \pm SD (Range) \\
\hline Age $(\mathrm{yr})$ & $118(100)$ & $29.1 \pm 5.7(20.0-40.0)$ \\
Height $(\mathrm{cm})$ & $118(100)$ & $181.6 \pm 7.1(158.8-203.2)$ \\
Body Mass (kg) & $118(100)$ & $90.6 \pm 15.59(56.7-141.0)$ \\
Time Since Traumatic Injury (yr) & $118(100)$ & $3.2 \pm 1.9(0.3-12.0)$ \\
Amputation Level & & - \\
TTA & $60(51)$ & - \\
TFA & $32(27)$ & - \\
BTTA & $12(10)$ & - \\
BTFA & $7(6)$ & - \\
TTA/TFA & $7(6)$ & - \\
Military Status & & - \\
Awaiting Disposition & $42(36)$ & \\
Active Duty-Nondeployed & $32(27)$ & \\
Retired from Armed Forces & $44(37)$ & \\
\hline
\end{tabular}

BTFA = bilateral transfemoral amputation, BTTA = bilateral transtibial amputation, SD = standard deviation, TFA = unilateral transfemoral amputation, TTA = unilateral transtibial amputation. 
JRRD, Volume 50, Number 7, 2013

Table 2.

Frequency of comorbidities in servicemembers with lower-limb loss.

\begin{tabular}{|c|c|c|c|c|}
\hline Medical Condition & TTA, $n(\%)$ & TFA, $n(\%)$ & BLLA, $n(\%)$ & Total, $n(\%)$ \\
\hline Total Participants & 60 & 32 & 26 & 118 \\
\hline Head Injury/Traumatic Brain Injury & $23(38)$ & $14(44)$ & $16(62)$ & $53(45)$ \\
\hline Depression & $12(20)$ & $7(22)$ & $5(19)$ & $24(20)$ \\
\hline Heterotopic Ossification on Residual Limb(s) & $16(27)$ & $20(63)$ & $17(65)$ & $53(45)$ \\
\hline
\end{tabular}

BLLA = bilateral lower-limb amputation, TFA = unilateral transfemoral amputation, TTA = unilateral transtibial amputation.

Table 3.

Comparison of 6-minute walk test (6MWT) distance and Amputee Mobility Predictor (AMP) scores for servicemembers with different levels of lower-limb loss.

\begin{tabular}{|c|c|c|c|}
\hline Outcome Measure & $\begin{array}{l}\text { TTA, Mean } \pm \text { SD } \\
\text { (Range) }\end{array}$ & $\begin{array}{l}\text { TFA, Mean } \pm \text { SD } \\
\text { (Range) }\end{array}$ & $\begin{array}{c}\text { BLLA, Mean } \pm \text { SD } \\
\text { (Range) }\end{array}$ \\
\hline Participants (n) & 60 & 32 & 26 \\
\hline AMP (points) ${ }^{* \dagger \ddagger}$ & $45.7 \pm 1.1(42-47)$ & $43.4 \pm 1.2(41-46)$ & $41.3 \pm 2.8(32-46)$ \\
\hline
\end{tabular}

Note: Significant difference was set to $p \leq 0.05$.

*Significant difference between those with TTA and TFA.

${ }^{\dagger}$ Significant difference between those with TTA and BLLA.

${ }^{\ddagger}$ Significant difference between those with TFA and BLLA.

BLLA = bilateral lower-limb amputation, SD = standard deviation, TFA = unilateral transfemoral amputation, TTA = unilateral transtibial amputation.

ambulated was consistent or exceeded that of MFCL K-level-4 for people with LLL, which is typical for active adults and athletes [22]. Differences in 6MWT distance were found between participants with TTA, TFA, and BLLA, but not between those with TFA and BLLA (Table 3). The CHAMP score demonstrated a strong positive relationship with 6MWT distance $(r=0.80, p<0.001)$. The results indicate that high CHAMP scores correlated with greater distance ambulated in 6 min.

The mean \pm SD for AMP performance for all participants was $43.8 \pm 3.1$ points, with a minimum and maximum score of 32 and 47, respectively. Differences in AMP performance were found between the three primary amputation groups (Table 3). The mean \pm SD for the CHAMP score was $21.9 \pm 7.8$, with a minimum and maximum score of 1 and 35, respectively. The CHAMP score demonstrated a strong positive relationship with AMP performance ( $r=0.87, p<0.001)$, indicating that high CHAMP scores correlated with high AMP scores.

The range of CHAMP item and total scores for SMs with limb loss overlapped with those of SM without limb loss (Table 4). The SMs without LLL were tested previously and were used to establish the reliability of the
CHAMP [27]. Three SMs with TTA (5\%) scored within the range of SMs without limb loss for SLS. Thirty-two SMs with TTA (53\%) and three with BTTA (25\%) scored within the range of SMs without limb loss for the ESST. Thirty-three SMs with TTA (55\%) and two with BTTA (16\%) scored within the range of SMs without limb loss for the T-Test. Thirty-seven SMs with TTA (62\%) and one with BTTA (8\%) scored within the range SMs without limb loss for the IAT. Three SMs with TTA (5\%) demonstrated CHAMP total scores that were within the range of SMs without limb loss.

ANOVA was used to compare differences in CHAMP item and CHAMP total scores by level of LLL (Table 5). Differences in SLS times were found between those with unilateral and bilateral LLL $(p<0.001)$, but when grouped by amputation level, the TTA and TFA groups with unilateral or bilateral LLL did not differ significantly. The ESST and IAT scores differed significantly between the TTA and TFA groups $(p<0.05)$ and between the TTA and BLLA groups $(p<0.05)$. There were significant differences among all three groups for both the T-Test and CHAMP score $(p<0.05)$. When examining by different levels of bilateral LLL, significant 
Table 4.

Descriptive statistics for Comprehensive High-Level Activity Mobility Predictor (CHAMP) test items for nondisabled Active Duty U.S. Army servicemembers and servicemembers with traumatic lower-limb loss.

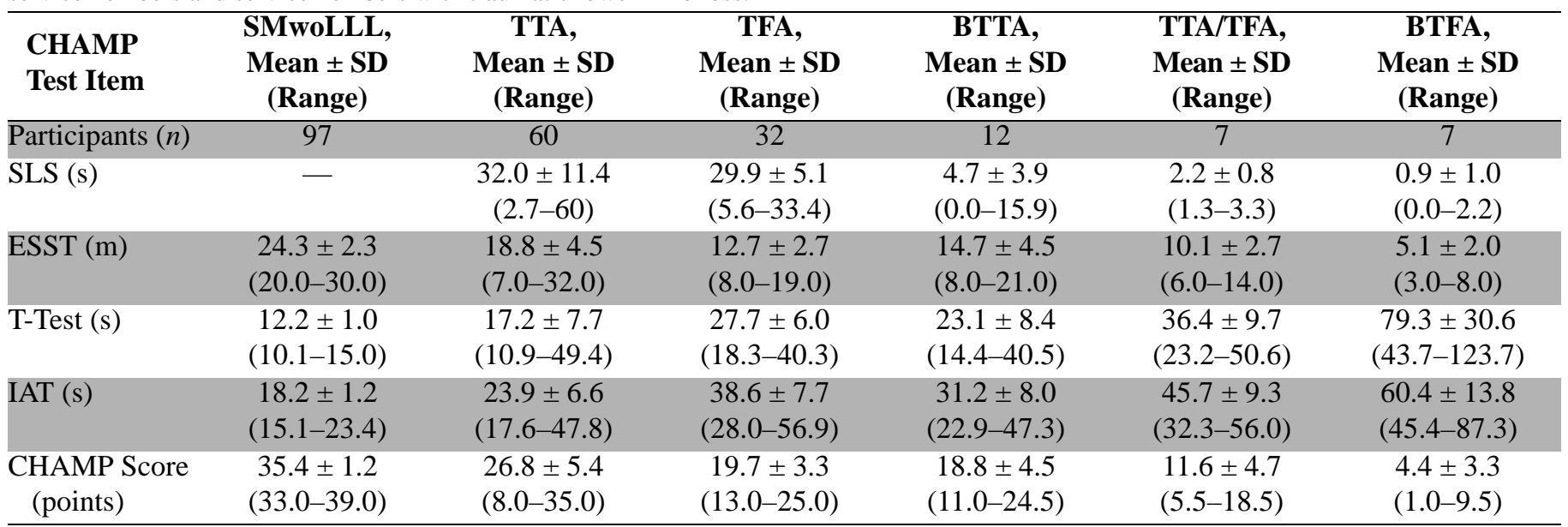

BTFA = bilateral transfemoral amputation, BTTA = bilateral transtibial amputation, ESST = Edgren Side Step Test, IAT = Illinois Agility Test, SD = standard deviation, SLS = Single Limb Stance, SMwoLLL = servicemember without lower-limb loss, TFA = unilateral transfemoral amputation, TTA = unilateral transtibial amputation.

Table 5.

Comparison of Comprehensive High-Level Activity Mobility Predictor (CHAMP) test items and CHAMP total score performance between three levels of amputation.

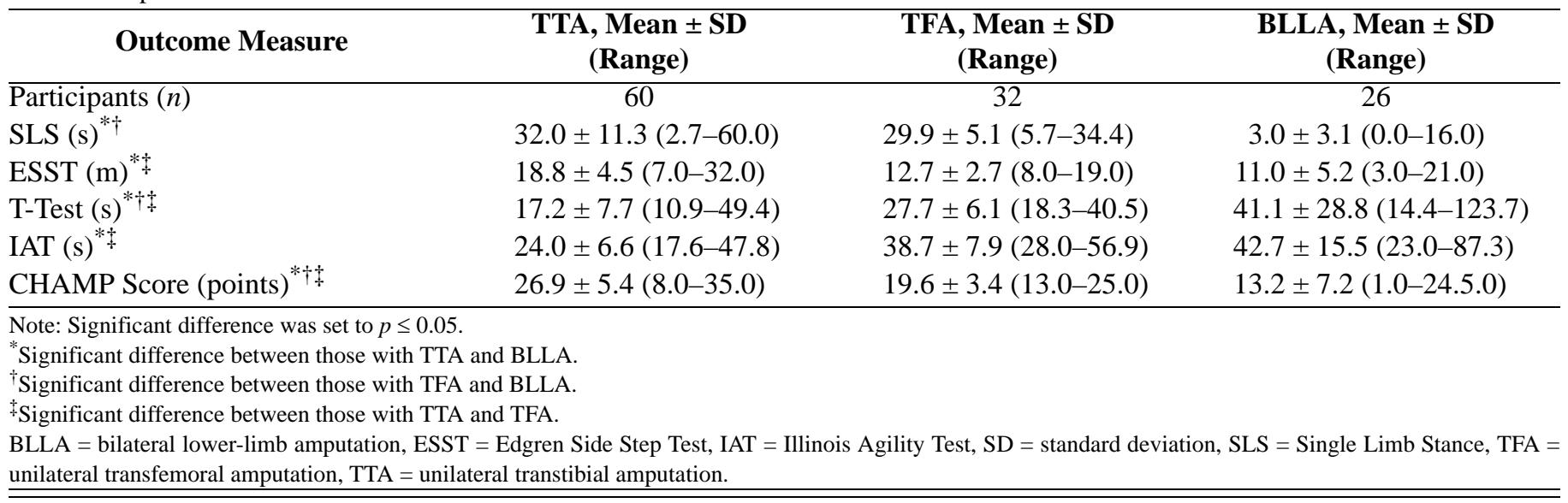

differences in CHAMP score were found between and within all levels of LLL $(p<0.05)$ except for those with TFA and BTTA (Table 4).

\section{DISCUSSION}

The CHAMP has been found to be a safe and reliable performance-based outcome measure that assesses highlevel mobility capabilities in SMs with traumatic LLL [27]. The purpose of this study was to determine the construct validity of the CHAMP with two methods: first, by examining the convergent validity between CHAMP score and outcome measures that assess a similar construct and second, by using the known groups methods to determine differences in high-level mobility, as measured by the CHAMP score, between SMs with different levels of amputation.

The convergent validity of the CHAMP was established using the 6MWT as a measure of overall mobility and physical function in people with LLL [22-23,37-38]. $6 \mathrm{MWT}$ performance has not been reported in the literature for a population of young fit males with traumatic LLL. The range in 6MWT performance (264-858 m) in 
this study indicated that, regardless of amputation or number of lower limbs lost, this population of wellrehabilitated SMs has the walking capacity consistent with civilian community ambulators to nondisabled peers at the highest fitness levels [39-40]. We anticipated that SMs who scored poorly on the CHAMP would walk a shorter distance in the 6MWT. Conversely, those with higher CHAMP scores indicating greater high-level mobility would ambulate greater distances in 6 min. The study results support these assumptions and validate the CHAMP as a measure of high-level mobility based on the strong positive correlation between 6MWT distance and CHAMP score.

Like the 6MWT, AMP performance has never been reported in the literature for a population of young SMs with traumatic LLL. We determined that an AMP score of 37 or better implies that, if the person with amputation is demonstrating proficient balance, postural stability, prosthetic control during sitting and standing, as well as the ability to vary walking cadence, he or she is ready to perform activities beyond basic locomotion [22]. The AMP was designed to measure function within the MFCL classification system, and therefore a ceiling effect for high-level activity was expected for those who exhibit functional mobility beyond the highest K-level, K-level-4. The CHAMP and AMP demonstrated such a strong, positive correlation $(r=0.87, p<0.001)$ because we had subject variability as per functional capabilities, level of amputation, and time since amputation, resulting in a wide variance in both AMP (32-47) and CHAMP (1-35) performance. We had participants who scored on the lower end of the AMP who walked the CHAMP to those who reached maximum scores on the AMP (47) and scored within the normal range of their nondisabled peers in the CHAMP (>33). Only two participants (both with TTA) scored maximum on the AMP and greater than a 33 on the CHAMP (34 and 35). More importantly, there was an area of overlap in performance where SMs have not achieved maximum scores on the AMP but can perform the CHAMP safely. While the AMP is a measure of basic mobility, the CHAMP is an appropriate measure of high-level mobility based on its component items. Because the CHAMP is designed to be performed with or without assistive devices, speed would be relative to each individual's mobility potential, where walking, jogging, or running would be acceptable. Together, these two instruments can provide clinicians with a continuum of performance-based assessment as the patients with LLL progress through the rehabilitation process. People with amputation who demonstrate higher AMP scores (32-47) have adequate balance with both static and lower-level dynamic activities, demonstrate better than average lower-limb power, and show competent use of their prosthesis. Once these patients have demonstrated these skills, they could be administered the CHAMP. As improvement in prosthetic ambulation and function occurs, the patients should begin to demonstrate the ability to perform higher-level activities such as stopping and starting movement, changing directions, and moving in multiple planes at a greater speed. As they continue to progress, the level of performance in terms of efficiency, coordination, speed, and agility should improve, resulting in higher CHAMP scores.

Performance-based measures of abilities that exceed those required for general mobility need to be available to assess those people with LLL who demonstrate advanced ambulation and mobility capabilities such as the ability to run and perform agility skills consistent with high level recreational activities, sports, and physically demanding jobs. Examples of those professions are those who serve in the military, firefighters, law enforcement officers, and professional athletes. The findings of this study demonstrated that a percentage of SMs with limb loss were able to achieve CHAMP scores equal to their nondisabled SM peers. The results support the CHAMP as a suitable measure of high-level mobility for people who have exceeded the AMP's ability to measure functional mobility and defined by the MFCLs.

Interestingly, almost half of those with TTA and a few with BTTA performed individual CHAMP items at the level of SMs without limb loss. For those with TTA or BTTA, the knee joint and subsequent use of the surrounding musculature can be used appropriately in performance of high-level mobility activities generating fast and explosive movement [41]. The presences of the knee joint enables participants to maintain posture, change directions faster, and maintain balance with greater ease, thus scoring better on all three agility tests. In addition, investigators observed greater use of the prosthesis to assist, rather than hinder, performance in SMs with TTA and BTTA. It appears that preservation of the knee joint(s) helped SMs with TTA and BTTA perform specific CHAMP items at the level of their nondisabled peers.

Differences in CHAMP item scores were not found across all levels of LLL. No differences in SLS were 
found between participants with unilateral LLL and those with BLLA, suggesting that balance and postural stability impairments affect these participants equally. Differences were not found between those with TFA, BTTA, and TTA/TFA for the ESST, T-Test, and IAT, suggesting that uniplanar, biplanar, and multiplanar movements are equally challenging for these groups. The individuals with TFA and BLLA undergo impairments to body structure and function with the loss of at least one knee joint and potentially two knee joints. Consequently, changes to the surrounding musculature result in alterations with respect to bone and muscle length, muscle size, and number of remaining muscle fibers, which alters the lowerlimb power generation of the residual $\operatorname{limb}(\mathrm{s})$ [42]. Diminished lower-limb power generation alters the ability of the person with amputation to perform fast, explosive movements necessary to quickly stop and start motion and change directions and body positions. For example, in order to change directions quickly in the frontal plane when performing the ESST or in the sagittal plane when pivoting such as in the IAT, it is necessary to be able to flex the knee joint and eccentrically contract the quadriceps femoris and gluteus maximus in order to produce a powerful concentric contraction leading to a fast explosive movement. In addition, the intact hamstrings are needed to allow the individual to stabilize the pelvis and lower the center of mass in order to assist with maximum power generation. Individuals with TFA and BLLA such as those with BTFA and TTA/TFA who are missing the knee joint(s) and original insertions of quadriceps femoris and hamstring muscles have to rely on hip adductors and abductors to produce movement in the frontal plane and change directions when pivoting in the sagittal plane, which results in less lower-limb power generation and slower movement. Lastly, because of the inability to flex their prosthetic knee voluntarily, they are unable to take advantage of the energy storage and return properties of carbon fiber prosthetic feet, thus relegating the prosthetic foot to a role of support and not energy production.

Yet when the scores for all four CHAMP items were combined to produce a composite CHAMP score, differences were found between the three main levels of lower limb and nearly all levels of LLL individually. These results support the use of the composite CHAMP score to assess high-level mobility because it provides a comprehensive view of the use physical performance factors of mobility in different planes of motion and under different conditions in SMs with traumatic LLL.

Future work should include exploring the potential of the CHAMP not only as a measure of high-level mobility but also as an instrument to assist with exercise prescription, examining specific movement patterns, determining the contribution of prosthetic components, and other variables that affect overall mobility. In addition, issues such as the effects of TBI, hearing loss, vision, and musculoskeletal issues need to be addressed. For example, while all participants in this study were screened for TBI, the subtle influences of cognition and motor performance on balance and high-activity mobility have not been determined.

\section{CONCLUSIONS}

The findings of the present study support the validity of the CHAMP as a comprehensive measure of highlevel mobility in SMs with LLL. The convergent construct validity and known group methods helped established the CHAMP's ability to assess and differentiate high-level mobility capabilities among the sample population. In summary, the CHAMP is a valid comprehensive measure of high-level mobility that assesses the person with amputation's capabilities and discriminates between people with LLL who are functioning at different levels.

\section{ACKNOWLEDGMENTS}

\section{Author Contribution:}

Study concept and design: R. S. Gailey, I. A. Gaunaurd, M. A. Raya, K. E. Roach.

Acquisition of data: P. D. Stoneman, A. A. Linberg, S. M. Campbell. Analysis and interpretation of data: R. S. Gailey, I. A. Gaunaurd, K. E. Roach.

Drafting of manuscript: R. S. Gailey, I. A. Gaunaurd, M. A. Raya. Critical revision of manuscript of important intellectual content: M. A. Raya, R. S. Gailey, I. A. Gaunaurd, K. E. Roach, C. Scoville, P. D. Stoneman, A. A. Linberg, S. M. Campbell.

Statistical analysis: I. A. Gaunaurd, K. E. Roach.

Study supervision: R. S. Gailey, I. A. Gaunaurd, C. Scoville.

Financial Disclosure: The authors have declared that no competing interests exist.

Funding Support: This material was based on work supported by the Military Amputee Research Program and the Telemedicine and Advanced Technology Research Center (Prime Award No. W81XWH06-2-0073). The U.S. Army Medical Research Acquisition Activity, Fort Detrick, Maryland, is the awarding and administering acquisition office. It was administered by the Henry M. Jackson Foundation for 
the Advancement of Military Medicine Inc and the South Florida Veterans Affairs Foundation for Research and Education Inc.

Additional Contributions: The authors would like to thank LTC Daniel M. Jayne, MPT, OCS; COL (Ret) Rebecca Hooper, PhD, PT; SGM (Ret) Brad Halling, CP; Carlos Gomez-Orozco; Orlando Gomez-Marin, MSc, PhD; Justin Z. Laferrier, PhD, MSPT, OCS, SCS, ATP, CSCS; John R. Fergason, CPO; Peter D. Harsch, CP; CAPT (Ret) Kathy Goldberg, MSPT; Matt Berliner, DPT; Jen Berrios, DPT; Todd Bowen, DPT; Sarah Carballo, DPT; Marcos Davy, DPT; Kayla Felderhoff, DPT; Erica Gagne, DPT; Heather Ganyard, DPT; Erick Harada, DPT; Justin Knapp-Wood, DPT; Carolyn Lindsay, DPT; Emily Lo, DPT; Megan Manniko, DPT; Patrick G. Manrique, DPT; Karrie McDonough, DPT; Daniel G. Muller, DPT; Tiffany Palmisano, DPT; Jeremiah Randall, DPT, ATC; Emily Roberts, DPT; Jarrod Schechla, DPT; Catherine Stewart, DPT; Adam Stivala, DPT; and Christen Tucker, DPT, for their dedication and countless hours of work to make this project a success. The authors also thank the staff at the Frederick Physical Fitness Center, Funk Physical Fitness Center, and Womack Army Medical Center in Fort Bragg; Center for the Intrepid, BAMC; Military Advanced Training Center, WRAMC; Amputee Care, Prosthetics, and Rehabilitation Department, Naval Medical Center San Diego; Research Department, Miami Department of Veterans Affairs (VA) Healthcare System; and Challenged Athletes Foundation for their generous support of this project. Dr. Stoneman is now with the Department of Physical Therapy, Rocky Mountain University of Health Professions, Provo, Utah. Mr. Campbell is now with the San Antonio Military Medical Center, Fort Sam Houston, Texas. Mr. Scoville is now with the Department of Rehabilitation, Walter Reed National Military Medical Center, Bethesda, Maryland. Ms. Linberg is now with the Department of Defense-VA Extremity Trauma and Amputation Center of Excellence, Department of Rehabilitation, Walter Reed National Military Medical Center, Bethesda, Maryland.

Institutional Review: Approved by the Institutional Review Board at Womack Army Medical Center, WRAMC Department of Clinical Investigation, WRAMC Human Use Committee (HUC), BAMC Department of Clinical Investigation, BAMC HUC, Army Clinical Investigation Regulatory Office, and Human Studies Subcommittee at the Miami VA Healthcare System.

Participant Follow-Up: The authors plan to inform participants of the publication of this study.

Disclaimer: The views expressed in this article are those of the authors and do not reflect the official policy or position of the Department of the Army, Department of the Navy, Department of Defense, or U.S. Government.

\section{REFERENCES}

1. World Health Organization. ICF browser: Chapter 4 mobility [Internet]. Geneva (Switzerland): WHO; 2012 [cited 2010 Feb 2]. Available from:

http://apps.who.int/classifications/icfbrowser/

2. United States Army Center for Health Promotion and Preventive Medicine. IET standardized physical training guide. Washington (DC): Department of the Army; 2005.
3. Lord SR, Menz HB. Physiologic, psychologic, and health predictors of 6-minute walk performance in older people. Arch Phys Med Rehabil. 2002;83(7):907-11.

[PMID:12098148]

http://dx.doi.org/10.1053/apmr.2002.33227

4. Walker CR, Ingram RR, Hullin MG, McCreath SW. Lower limb amputation following injury: A survey of long-term functional outcome. Injury. 1994;25(6):387-92.

[PMID:8045644]

http://dx.doi.org/10.1016/0020-1383(94)90132-5

5. Reiber GE, McFarland LV, Hubbard S, Maynard C, Blough DK, Gambel JM, Smith DG. Servicemembers and veterans with major traumatic limb loss from Vietnam war and OIF/ OEF conflicts: Survey methods, participants, and summary findings. J Rehabil Res Dev. 2010;47(4):275-97.

[PMID:20803399]

http://dx.doi.org/10.1682/JRRD.2010.01.0009

6. Dougherty PJ, McFarland LV, Smith DG, Esquenazi A, Blake DJ, Reiber GE. Multiple traumatic limb loss: A comparison of Vietnam veterans to OIF/OEF servicemembers. J Rehabil Res Dev. 2010;47(4):333-48. [PMID:20803402] http://dx.doi.org/10.1682/JRRD.2009.04.0043

7. Portney LG, Watkins MP. Chapter 14: Surveys. In: Portney LG, Watkins MP, editors. Foundations of clinical research: Applications to practice. Upper Saddle River (NJ): Prentice Hall; 2000. p. 286-89.

8. Roach K. Measurement of health outcomes: Reliability, validity, and responsiveness. J Prosthet Orthot. 2006;18(1S): 8-12. http://dx.doi.org/10.1097/00008526-200601001-00003

9. Gailey R. Predictive outcome measures versus functional outcome measures in the lower limb amputee. J Prosthet Orthot. 2006;18(1S):51-60. http://dx.doi.org/10.1097/00008526-200601001-00006

10. Deathe AB, Wolfe DL, Devlin M, Hebert JS, Miller WC, Pallaveshi L. Selection of outcome measures in lower extremity amputation rehabilitation: ICF activities. Disabil Rehabil. 2009;31(18):1455-73. [PMID:19479574] http://dx.doi.org/10.1080/09638280802639491

11. Powell LE, Myers AM. The Activities-specific Balance Confidence (ABC) Scale. J Gerontol A Biol Sci Med Sci. 1995;50A(1):M28-34. [PMID:7814786] http://dx.doi.org/10.1093/gerona/50A.1.M28

12. Shumway-Cook A, Brauer S, Woollacott M. Predicting the probability for falls in community-dwelling older adults using the Timed Up \& Go Test. Phys Ther. 2000;80(9):896903. [PMID:10960937]

13. Nelson AJ. Functional ambulation profile. Phys Ther. 1974;54(10):1059-65. [PMID:4424703]

14. Berg KO, Maki BE, Williams JI, Holliday PJ, WoodDauphinee SL. Clinical and laboratory measures of postural balance in an elderly population. Arch Phys Med Rehabil. 1992;73(11):1073-80. [PMID:1444775] 
15. Funk SG, Tornquist EM, Copp LA, editors. Key aspects of recovery: Improving nutrition, rest, and mobility. New York (NY): Springer; 1990.

16. Sharp M, Knapik J, Walker L, Burrell L, Frykman P, Darakjy S, Lester ME, Marin RE. Physical fitness and body composition after a 9-month deployment to Afghanistan. Med Sci Sports Exerc. 2008;40(9):1687-92. [PMID:18685520] http://dx.doi.org/10.1249/MSS.0b013e318176b978

17. Harman EA, Gutekunst DJ, Frykman PN, Sharp MA, Nindl BC, Alemany JA, Mello RP. Prediction of simulated battlefield physical performance from field-expedient tests. Mil Med. 2008;173(1):36-41. [PMID:18251329]

18. Mello RP, Murphy M, Vopel J. Relationship between a Two Mile Run for Time and Maximal Oxygen Uptake. J Strength Conditioning Res. 1988;2(1):9-12.

19. Bolgla LA, Keskula DR. Reliability of lower extremity functional performance tests. J Orthop Sports Phys Ther. 1997;26(3):138-42. [PMID:9276854]

20. Gailey RS, Gaunaurd IA, Raya MA, Roach KE, Linberg AA, Campbell SM, Jayne DM, Scoville C. Development and reliability testing of the Comprehensive High-Level Activity Mobility Predictor (CHAMP) in male servicemembers with traumatic lower-limb loss. J Rehabil Res Dev. 2013; 50(7):905-18. http://dx.doi.org/10.1682/JRRD.2012.05.0099

21. Streiner DL, Norman GR. Chapter 10: Validity. In: Streiner DL, Norman GR, editors. Health measurement scales: A practical guide to their development and use. 3rd ed. New York (NY): Oxford University Press; 2003. p. 172-93.

22. Gailey RS, Roach KE, Applegate EB, Cho B, Cunniffe B, Licht S, Maguire M, Nash MS. The amputee mobility predictor: An instrument to assess determinants of the lowerlimb amputee's ability to ambulate. Arch Phys Med Rehabil. 2002;83(5):613-27. [PMID:11994800]

23. Lin SJ, Bose NH. Six-minute walk test in persons with transtibial amputation. Arch Phys Med Rehabil. 2008; 89(12):2354-59. [PMID:18976979] http://dx.doi.org/10.1016/j.apmr.2008.05.021

24. Pasquina P, Fitzpatrick K. The Walter Reed experience: Current issues in the care of the traumatic amputee. J Prosthet Orthot. 2006;18(1S):119-22. http://dx.doi.org/10.1097/00008526-200601001-00015

25. Fischer H. United States military casualty statistics: Operation Iraqi Freedom and Operation Enduring Freedom. In: Congressional Research Service Report for Congress. Washington (DC): Congressional Research Service; 2009.

26. Stinner DJ, Burns TC, Kirk KL, Ficke JR. Return to duty rate of amputee soldiers in the current conflicts in Afghanistan and Iraq. J Trauma. 2010;68(6):1476-79.

[PMID:20068483]

http://dx.doi.org/10.1097/TA.0b013e3181bb9a6c
27. Gailey RS, Raya M, Gaunaurd IA, Roach KE, Gaunaurd I, Scoville C, Linberg A, Jayne D, Campbell S. The validity and reliability of the Comprehensive High-Level Activity Mobility Predictor (CHAMP) established for military service members with traumatic lower limb loss. J Orthopaedic Sports Phys Ther. 2011;41:A46-47.

28. Bohannon RW, Larkin PA, Cook AC, Gear J, Singer J. Decrease in timed balance test scores with aging. Phys Ther. 1984;64(7):1067-70. [PMID:6739548]

29. Semenick D. Testing protocols and procedures. In: Baechle T, editor. Essentials of strength training and conditioning. 1st ed. Champaign (IL): Human Kinetics; 1994. p. 258-73.

30. Harman E, Pandorf C. Principles of test selection and administration. In: Baechle T, Earle R, editors. Essentials of strength training and conditioning. 2nd ed. Champaign (IL): Human Kinetics; 2000. p. 275-311.

31. Edgren HD. An experiment in the testing of ability and progress in basketball. Res Quart Am Phys Ed Assoc. 1932;3(1):159-71.

32. Miller MG, Herniman JJ, Ricard MD, Cheatham CC, Michael TJ. The effects of a 6-week plyometric training program on agility. J Sport Sci Med. 2006;5:459-65.

33. Cureton T. Chapter 5: General motor fitness characteristics and strength of champions. In: Cureton T, editor. Physical fitness of champion athletes. Urbana (IL): University of Illinois Press; 1951. p. 67-69.

34. Roozen M. Action-reaction: Illinois Agility Test. NSCA Perform Training J. 2008;3(5):5-6.

35. Mossberg KA, Fortini E. Responsiveness and validity of the six-minute walk test in individuals with traumatic brain injury. Phys Ther. 2012;92(5):726-33. [PMID:22282772] http://dx.doi.org/10.2522/ptj.20110157

36. ATS Committee on Proficiency Standards for Clinical Pulmonary Function Laboratories. ATS statement: Guidelines for the six-minute walk test. Am J Respir Crit Care Med. 2002;166(1):111-17. [PMID:12091180] http://dx.doi.org/10.1164/ajrccm.166.1.at1102

37. Raya MA, Gailey RS, Fiebert IM, Roach KE. Impairment variables predicting activity limitation in individuals with lower limb amputation. Prosthet Orthot Int. 2010;34(1):73-84. [PMID:20196689] http://dx.doi.org/10.3109/03093640903585008

38. Resnick L, Borgia M. Reliability of outcome measures for people with lower-limb amputation: Distinguishing true change from statistical error. Phys Ther. 2011;91(4):1-11.

39. Gailey RS, Campbell S, Gaunaurd I, Raya MA, Harada EK, Lo E, Randall J, Roberts FC, Schechla J. Normative 6minute walk test values for healthy young men. J Orthopaedic Sports Phys Ther. 2009;39:A115.

40. Gailey R. The amputee mobility predictor: A functional assessment instrument for the prediction of the lower limb 
JRRD, Volume 50, Number 7, 2013

amputees readiness to ambulate. Glascow (Scotland): University of Strathclyde; 1999.

41. Tyler TF, Cuoco A. Plyometric training. In: Andrews JR, Harrelson GL, Wilk KE, editors. Physical rehabilitation of the injured athlete. Philadelphia (PA): Saunders; 2004. p. 265-71.

42. Jaegers SM, Arendzen JH, de Jongh HJ. Prosthetic gait of unilateral transfemoral amputees: A kinematic study. Arch Phys Med Rehabil. 1995;76(8):736-43. [PMID:7632129] http://dx.doi.org/10.1016/S0003-9993(95)80528-1

Submitted for publication May 30, 2012. Accepted in revised form December 6, 2012.

This article and any supplementary material should be cited as follows:
Gailey RS, Scoville C, Gaunaurd IA, Raya MA, Linberg AA, Stoneman PD, Campbell SM, Roach KE. Construct validity of Comprehensive High-Level Activity Mobility Predictor (CHAMP) for male servicemembers with traumatic lower-limb loss. J Rehabil Res Dev. 2013;50(7): 919-30.

http://dx.doi.org/10.1682/JRRD.2012.05.0100

ResearcherID/ORCID: Robert S. Gailey, PhD, PT: I-34582013; Ignacio A. Gaunaurd, PhD, MSPT: I-3490-2013

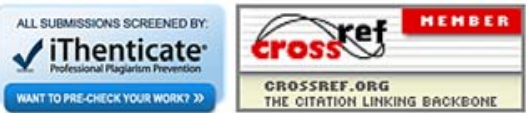

